\title{
PPARa, a predictor of patient survival in glioma, inhibits cell growth through the E2F1/miR-19a feedback loop
}

\author{
Yan Shi ${ }^{1, *}$, Tao Tao ${ }^{1, *}$, Ning Liu ${ }^{1, *}$, WenKang Luan ${ }^{1, *}$, Jin Qian ${ }^{1,2}$, Rui Li ${ }^{1}$, Qi Hu ${ }^{1}$, Yan \\ Wei $^{1}$, Junxia Zhang ${ }^{1}$, Yongping You ${ }^{1}$ \\ ${ }^{1}$ Department of Neurosurgery, The First Affiliated Hospital of Nanjing Medical University, Nanjing, China \\ ${ }^{2}$ Department of Neurosurgery, People's Hospital of Xuancheng City, Anhui, China \\ *These authors contributed equally to this work \\ Correspondence to: Yongping You, email: YYPL9@njmu.edu.cn \\ Junxia Zhang, email: zjx232@126.com
}

Keywords: PPARa, E2F1, miR-19a, RB, feedback loop

Received: March 19, $2016 \quad$ Accepted: October 28, 2016

Published: November 07, 2016

\section{ABSTRACT}

Nuclear receptors such as peroxisome proliferator-activated receptor a (PPARa) are potential therapeutic targets. In this study, we found that PPARa expression was lower in high grade gliomas and PPARa was an independent prognostic factor in GBM patients. PPARa agonism or overexpression inhibited glioma cell proliferation, invasion, and aerobic glycolysis as well as suppressed glioma growth in an orthotopic model. Bioinformatic analysis and luciferase reporter assays showed that miR-19a decreased PPARa expression. E2F1 knockdown up-regulated PPARa and inhibited cell proliferation, invasion, and aerobic glycolysis, but this activity was blocked by miR-19a. Knockdown of E2F1 decreased miR-19a by inhibiting the miR-19a promoter. Moreover, PPARa repressed E2F1 via the p21 pathwayby modulating the transcriptional complexes containing E2F1 and PRB proteins. These results suggest that the E2F1/miR19a/PPARa feedback loop is critical for glioma progression.

\section{INTRODUCTION}

The peroxisome proliferator-activated receptor $\alpha$ $(P P A R \alpha)$ is part of a family of ligand-activated nuclear steroid hormone receptors [1] act as transcription factors $[2,3]$. After ligand binding, PPAR $\alpha$ heterodimers with retinoid X receptors (RXR) and binds to specific DNA sequences to regulate expression of target genes[4]. PPAR $\alpha$ activation is involved in glucose, lipid, and amino acid metabolism [5] and regulates a number of physiological processes including cell proliferation, apoptosis, inflammation, and oxidative stress $[6,7]$.

The link between PPAR $\alpha$ and cancer was first made after PPAR $\alpha$ agonists were shown to increase the incidence of liver tumors in rodents $[8,9]$. This finding was not replicated in humans, and consequently, PPAR $\alpha$ is not an established molecular target for cancer therapy. However, recent studies found reduced levels of PPAR $\alpha$ in some tumor types [10-12], while PPAR $\alpha$ agonists can suppress tumor growth [13] [14]. The PPAR $\alpha$ agonist, fenofibrate, induces human HepG2 cell death by increasing the levels of reactive oxygen species (ROS) and depleting intracellular (GSH) [15]. PPAR $\alpha$ activation also suppresses the metastatic potential of melanoma in vitro and in vivo $[16,17]$. Nonetheless, in other cancers, including kidney [12] and hepatocellular carcinoma [18], PPAR $\alpha$ has also been found to lead to the progression of tumor growth. Thus, the biological function of PPAR $\alpha$ in human cancers is still controversial and its role needs further investigation.

This study explores the clinical features, biological functions and potential mechanisms of action of PPAR $\alpha$ in glioma both in vitro and in vivo. We found that PPAR $\alpha$ is associated with glioma grade and GBM survival. PPAR $\alpha$ inhibits glioma cell proliferation, invasion, and aerobic glycolysis, and suppresses glioma growth in an orthotopic model via a positive feedback loop with E2F1 and miRNA-19a.

\section{RESULTS}

Lower PPAR $\alpha$ expression is associated with poorer clinical outcomes in glioma patients

PPAR $\alpha$ expression was analyzed in whole genome gene profiling of 158 glioma tissues based on Chinese Glioma Genome Atlas (CGGA) data. PPAR $\alpha$ expression was significant lower in high grade gliomas (HGG) 
compared to low grade gliomas (LGG) (Figure 1A). Two employed two independent glioma gene expression data sets (Rembrandt data and GSE4290 data) were uesd to examine the association between PPAR $\alpha$ expression levels and glioma grade (Figure S1A). PPAR $\alpha$ was associated with tumor grade $(P<0.0001$ for both Rembrandt data and GSE4290 data), which is consistent with the CGGA data. PPAR $\alpha$ expression was measured in 5 normal brain tissues and 20 glioma tissues using qRT-PCR and a similar trend of low expression of PPAR $\alpha$ in glioma tissues was observed (Figure 1B). GBM samples expressing lower than a median level of PPAR $\alpha$ were associated with decreased survival relative to those with PPAR $\alpha$ levels higher than the median $(P=0.016)$ in the CGGA data (Figure 1C). Moreover, PPAR $\alpha$ expression was positively correlated with overall survival based on Rembrandt and GSE4290 data (Figure S1B). Overall, these data suggest that PPAR $\alpha$ inactivation may play an important role in glioma development and survival prediction.

\section{PPARa is an independent prognostic factor in GBM patients}

Univariate Cox regression analysis was performed using clinical and genetic variables for 89 GBM patients from the CGGA. High expression of PPAR $\alpha$, high Karnofsky Performance Status (KPS) score, total tumor resection, and high levels of the proliferation markers, Ki-67, PCNA, P170 and high TOPO II were all associated with overall survival, whereas gender and increasing age were not (Table 1). Interestingly, high expression of PPAR $\alpha$ was associated with gender $(P=0.043)$, and older age at diagnosis $(P=0.001)$ (Table S1). We evaluated the factors that contribute to overall survival with a multivariate Cox proportional hazards model. PPAR $\alpha$ expression, KPS score, and total resection all correlated independently with overall survival $(\mathrm{HR}=0.465$, $P=0.006 ; \mathrm{HR}=0.389, P=0.002 ; \mathrm{HR}=0.503, P=0.042$; respectively) when considering gender, Ki-67, P170, PCNA and TOPO II expression $(P<0.2$, univariate Cox regression analysis).

\section{PPARa suppresses glioma growth in vitro and in an orthotopic model}

To determine the biological functions of PPAR $\alpha$, PPAR $\alpha$ expression were transfected with PPAR $\alpha$ lentivirus (Figure S2A). Overexpression of PPAR $\alpha$ in both U87 and LN229 glioma cells with low endogenous PPAR $\alpha$ expression inhibited cell colony formation, invasion, and glucose consumption (Figure $2 \mathrm{~A}-2 \mathrm{C}$ and Supplementary Figure S2B and S2C). We verifed the inhibitory effect of PPARa on glioma cells by adding fenofibrate to our cultures. Fenofibrate also notably suppressed glioma cell proliferation, invasion and aerobic glycolysis (Supplementary Figure S2D-S2F).
To further investigate the role of PPAR $\alpha$ in tumor growth of glioma in vivo, we extended our investigation by intracranial implantation of PPAR $\alpha$ overexpressing U87 cells in nude mice. Bioluminescence imaging showed tumor growth stasis in the overexpressing PPAR $\alpha$ group compared with the control group and on day 10, a statistically significant difference in tumor volume emerged between the 2 groups (Figure 2D and 2E). Moreover, overexpression of PPAR $\alpha$ markablely prolonged the survival time of glioma-bearing mice (Figure 2F).

Both Akt and Erk1/2 play a role in malignant progression, thus, we evaluated phosphorylation of these proteins after fenofibrate treatment [17]. Fenofibrate reduced Akt and Erk1/2 phosphorylation. To prove that these effects were PPAR $\alpha$ dependent, we tranduced si-PPAR $\alpha$ into cells before fenofibrate treatment. As shown in Figure 2G, si-PPAR $\alpha$ abolished the role of fenofibrate indicating PPAR $\alpha$ may affect cellular behavior in glioma by inhibiting the phosphorylation status of Akt and Erk1/2.

\section{E2F1/miR-19a negatively regulates PPAR $\alpha$ in glioma cells}

We used bioinformatic analysis, TargetScan and PicTar, to investigate the upstream of PPAR $\alpha$ in glioma cells. We identified PPAR $\alpha$ as the potential target of miR-19a (Figure 3A). Western blot analysis showed that PPAR $\alpha$ expression was increased in glioma cells with down-regulation of miR-19a (Figure 3B). We determined the direct interaction between miR-19a and its binding site within PPAR $\alpha$ mRNA, usingluciferase reporter constructs containing either wild-type (pGL3-WT- PPAR $\alpha-3^{\prime}$ UTR) or mutant (pGL3-MUT- PPAR $\alpha-3^{\prime}$ UTR) PPAR $\alpha$ 3'UTRs transfected into glioma cells. MiR-19a could influence luciferase activity of the pGL3-WT- PPAR $\alpha-3$ 'UTR plasmid in U87 and LN229 cells without significantly changing activity of the pGL3-MUT- PPAR $\alpha-3$ 'UTR plasmid (Figure 3C and 3D). These data provide evidence that miR-19a directly suppresses PPAR $\alpha$ expression by binding to the $3^{\prime} \mathrm{UTR}$ of PPAR $\alpha$ mRNA in gliomas.

The expression of miR-19a was significantly higher in HGG than LGG, and a reduction in miR-19a inhibited glioma cell proliferation, invasion and aerobic glycolysis (Supplementary Results and Figure S3). E2F transcription factors can directly bind the promoter of the miR-17-92 cluster regulating its transcription[19]. Thus, microarrays combined with Pearson correlation analysis revealed that the miR-17-92 cluster was positively correlated with E2F1 in glioma cells (Figure 3E). siRNA knockdown of E2F1 decreased miR-19a expression (Figure 3F). Further, we created a construct containing the miR-19a promoter (miPPR-19a) showed reduced activity in si-E2F1 cells (Figure 3G), while up-regulation of E2F1 using an overexpression construct notably enhanced miPPR-19a activity (Figure $3 \mathrm{H}$ ). Taken together, these results show that E2F1 increases miR-19a expression. 
Next, we analyzed the E2F1 expression pattern in CGGA data and verified it in 25 tissues samples. As shown in Figure 4A and 4B, E2F1 was higher in the HGG samples than in the LGG samples. Kaplan-Meier survival curve analysis showed that high expression of E2F1 confers a poor prognosis in GBM patients (Figure 4C). si-E2F1 triggered the inhibition of glioma cell proliferation, invasion and aerobic glycolysis (Figure 4D-4F and Supplementary Figure S4A and S4B). Furthermore, increased miR-19a in E2F1-depleted cells largely blocked the effect of si-E2F1 on the suppression the malignant progression and the decreased PPAR $\alpha$ expression in glioma cells (Figure 4G), suggesting that E2F1 enhances malignant glioma progression by decreasing PPAR $\alpha$ expression in a miR-19a-dependent manner.

\section{PPAR $\alpha$ activation feedback represses E2F1 activation by modulating transcriptional complexes formed with E2F1 and pRB proteins}

To determine whether PPAR $\alpha$ feedback regulates the expression or trans-activation of E2F1 through a PPAR $\alpha$ dependent mechanism, we analyzed the sequence of the E2F1 promoter region. There was no PPAR-response element (PPRE), suggesting that E2F1 may be modulated by PPAR $\alpha$ via an indirect mechanism. PPAR $\alpha$ activation increases $\mathrm{p} 16$ protein levels through direct DNA binding to the p16 promoter [20]. P16 protein is a tumor suppressor belongings to the super-family of cyclin-dependent kinase (CDK) inhibitors (CDKI)[21]. These proteins inhibit cellcycle progression by preventing the association of CDKs with cyclins(CYCs), and initiate RB phosphorylation by $\mathrm{CYC} / \mathrm{CDK}$ complexes $[22,23]$. PPAR $\alpha$ agonist treatmentenhanced p21 (another CDKI family member) protein levels in U87 and LN229 cells and decreased the ratio of phosphorylated/non-phosphorylated RB (Figure 5A). Because the trans-activation potential of $\mathrm{E} 2 \mathrm{~F}$ is repressed by the RB family of proteins through the formation of E2F/RB complexes [24], and $\mathrm{RB}$ phosphorylation can disrupt E2F/RB complexes, we hypothesized that PPAR $\alpha$ regulates the biological function of E2F1 by interfering with E2F/RB complexes via the p21 signaling pathway. Co-immunoprecipitation (co-IP) assays showed that E2F1 coprecipitated with RB in protein lysates isolated from U87 and LN229 cells. In addition, PPAR $\alpha$ activation resulted in increased binding of E2F1 to the RB. These results indicate that PPAR $\alpha$
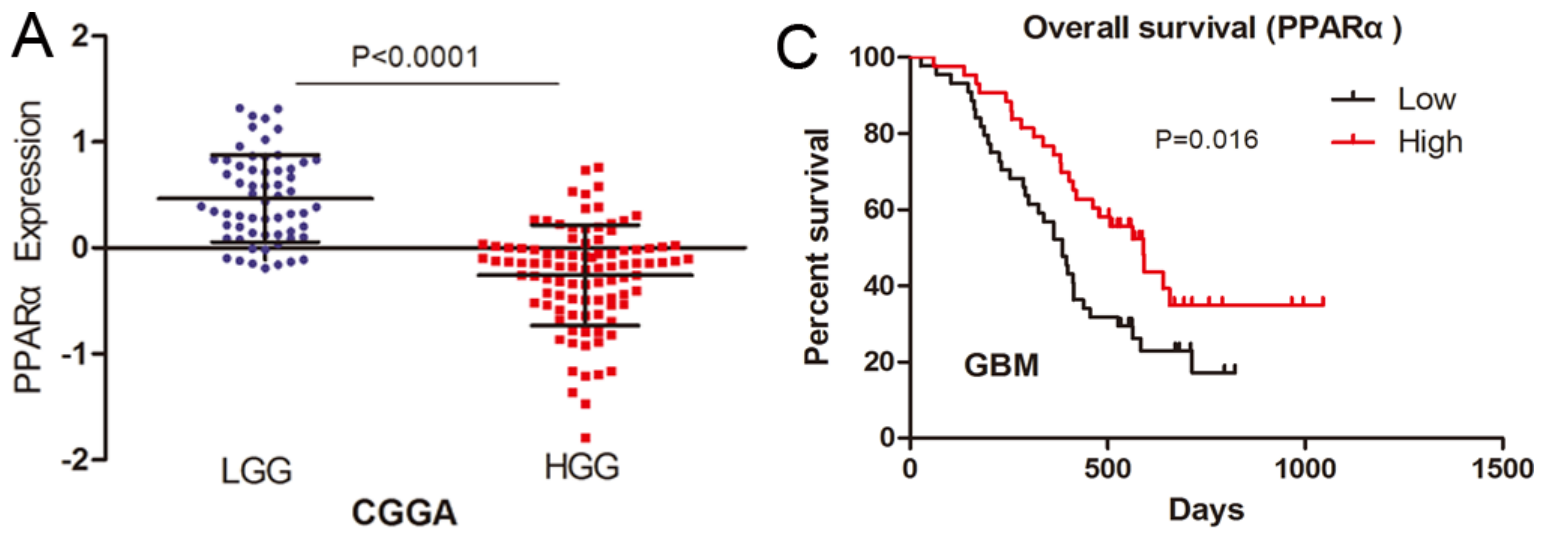

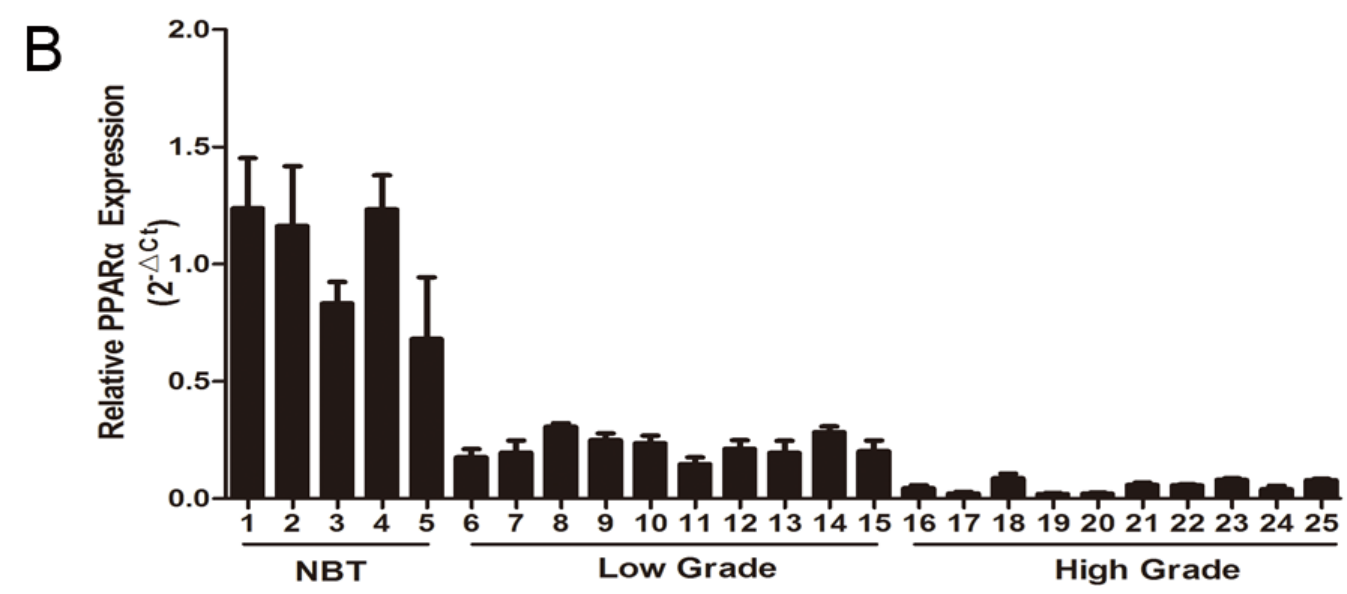

Figure 1: PPAR $\alpha$ expression in glioma tissues of the CGGA glioma dataset (61 cases of low grade glioma [LGG], 97 cases of high grade glioma [HGG]). (A) PPAR $\alpha$ expression was significantly lower in HGGtissues than in LGG tissues. (B) qRTPCR confirmation of reduced PPAR $\alpha$ levels in HGG tissues compared with LGG tissues and normal brain tissues. (C) Kaplan-Meier survival curves for PPAR $\alpha$ expression in glioma tissues of the CGGA dataset. Low expression of PPAR $\alpha$ confers a poor prognosis in glioma patients. 
Table 1: Cox proportional hazard regression analyses of PPAR $\alpha$ expression and other characteristics in relation to overall survival in GBM patients

\begin{tabular}{lcccc}
\hline \multirow{2}{*}{\multicolumn{1}{c}{ Variable }} & \multicolumn{2}{c}{ Univariable Regression } & \multicolumn{2}{c}{ Multivariable Regression } \\
\cline { 2 - 4 } & HR & $\boldsymbol{P}$ value & HR & $\boldsymbol{P}$ value \\
\hline Gender (Female/ Male) & 1.327 & 0.293 & & \\
Increasing age & 1.008 & 0.455 & & 0.002 \\
KPS score (> 80) & 0.310 & $<0.001$ & 0.389 & 0.042 \\
Total resection & 0.560 & 0.028 & 0.503 & \\
IDH1 mutation & 0.734 & 0.422 & & 0.006 \\
MGMT promoter methylation & 1.136 & 0.713 & & 0.438 \\
High PPAR $\alpha$ & 0.532 & 0.016 & 0.465 & \\
High Ki-67 & 1.508 & 0.127 & 1.275 & \\
High EGFR & 1.430 & 0.201 & & 0.013 \\
High MGMT & 0.905 & 0.966 & & 0.438 \\
High PCNA & 1.571 & 0.111 & 2.243 & \\
High P170 & 0.622 & 0.077 & 1.546 & 0.311 \\
High PTEN & 1.036 & 0.972 & & \\
High TOPO II & 1.618 & 0.087 & 1.394 & \\
High GST- $\pi$ & 1.393 & 0.217 & & \\
\hline
\end{tabular}
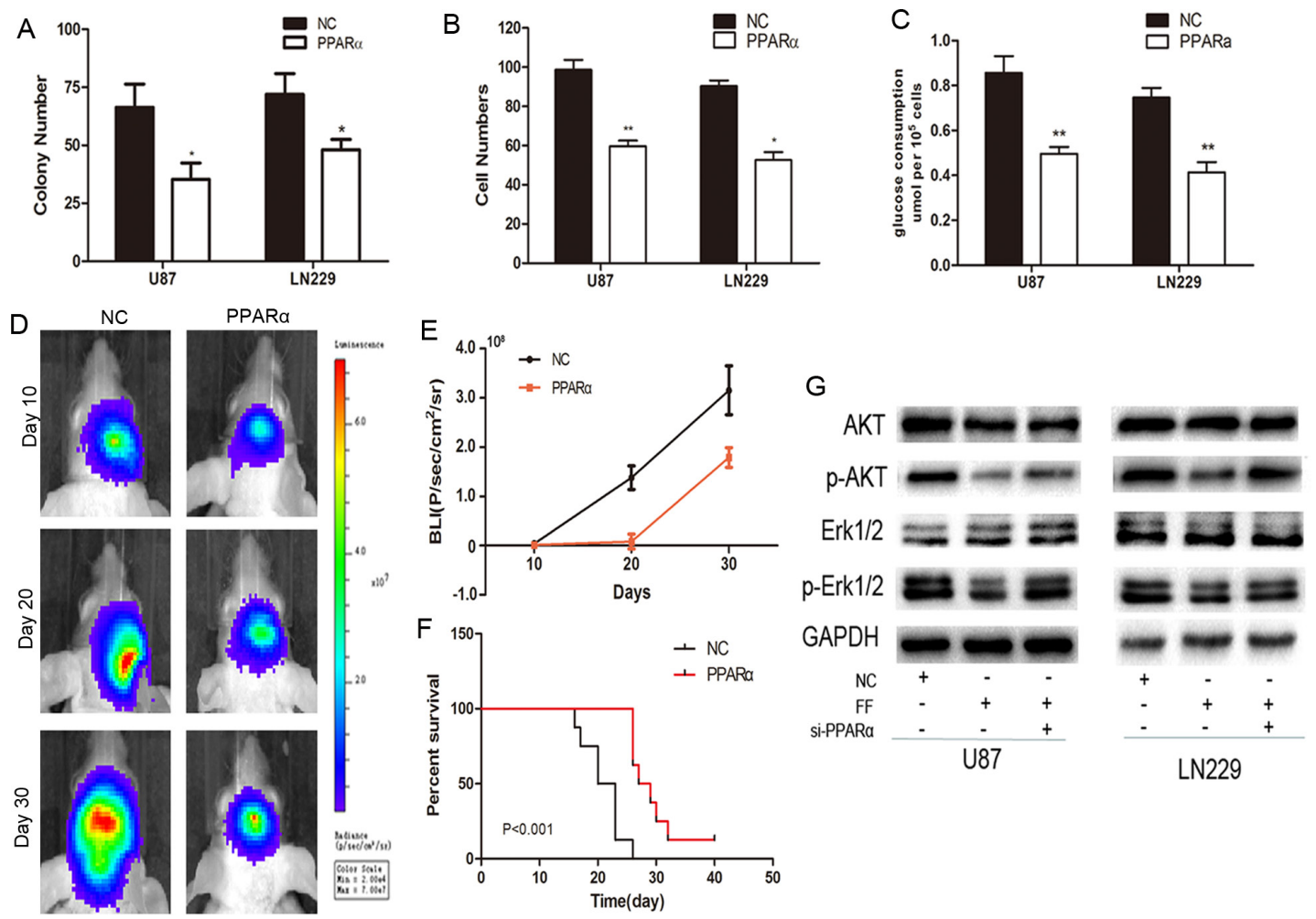

Figure 2: Effects of PPARa on glioma cell biology as evaluated with in vitro assays. (A) Overexpression of PPAR $\alpha$ decreased the number of colonies formed in plates. (B) Invasiveness of U87 and LN229 cells was attenuated by increased expression of PPAR $\alpha$. (C) Over-expression of PPAR $\alpha$ reduced the levels of aerobic glycolysis in U87 and LN229 cells. (D) Representative images of mice implanted with intracranial tumors on days 10, 20, and 30. (E) Plot of Fluc activity by bioluminescence imaging for intracranial tumors. (F) KaplanMeier survival curves for PPAR $\alpha$ expression in the two groups of mice. (G) The PPAR $\alpha$ agonist fenofibrate interferes with the Akt and Erk1/2 signaling pathways by decreasing Akt and Erk1/2 phosphorylation. The effect of fenofibrate on Akt and Erk1/2 phosphorylation in a PPAR $\alpha$-dependent manner. 
activation directly inhibits E2F1 activation by preventing the disruption of RB/E2F1 complexes, while RB binding inhibits the ability of E2F1 to form the protein-protein contacts required for activation and may serve as a transactivator. (Figure 5B and 5C).

\section{Clinical significance of E2F1/ miR-19a/ PPAR $\alpha$ feedback loop in glioma tissues}

Immunohistochemistry and in situ hybridization analysis revealed that E2F1 and miR-19a were increased in HGG in comparison with LGG, whereas PPAR $\alpha$ was decreased in HGG (Figure 6A and Supplementary Table S2). E2F1 and miR-19a expression were markedly decreased following upregulation of PPAR $\alpha$ in a nude mouse glioma xenograft model (Figure 6B). In glioma tissues, pearson correlation showed a significant positive correlation between E2F1 and miR-19a levels $(\mathrm{R}=0.66, P<0.01)$. An inverse correlation was detected between miR-19a and PPAR $\alpha(\mathrm{R}=-0.62, P<0.01)$, as well as PPAR $\alpha$ and E2F1 $(\mathrm{R}=-0.68, P<0.01)$.

\section{DISCUSSION}

Nuclear receptors are promising novel therapeutic targets for cancer treatments. Peroxisome proliferatoractivated receptors (PPARs), which belong to the nuclear hormone receptor super family and are ligandactivated transcription factors [11], are among these targets. PPAR $\alpha$ agonists suppress human colorectal carcinoma cell growth [25]. The PPAR $\alpha$ agonist fenofibrate suppresses tumor growth and angiogenesis by reducing endothelial cell proliferation and VEGF production and increasing endostatin [26]. In the current study, PPAR $\alpha$ has been identified as a critical marker not only of tumor grade but also for prognosis in glioma. PPAR $\alpha$ inhibited the malignant progression of glioma in vivo and in vitro. Our results show that PPAR $\alpha$ is an important factor for malignant progression survival in glioma patients and exhibits antitumor effects by reducing cell proliferation, invasion and aerobic glycolysis.
A

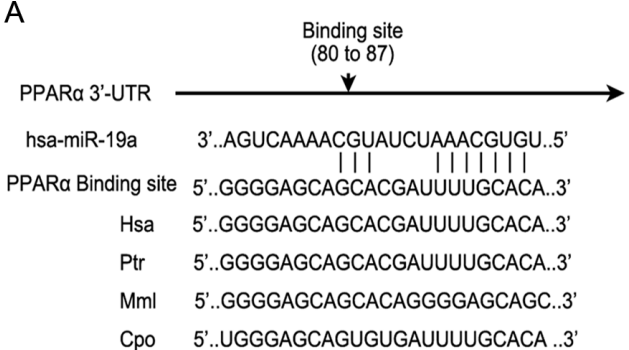

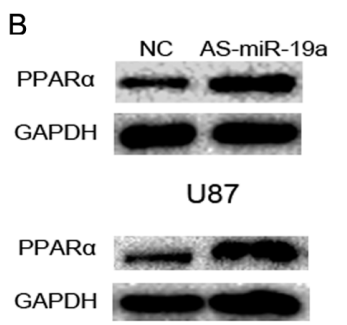

LN229

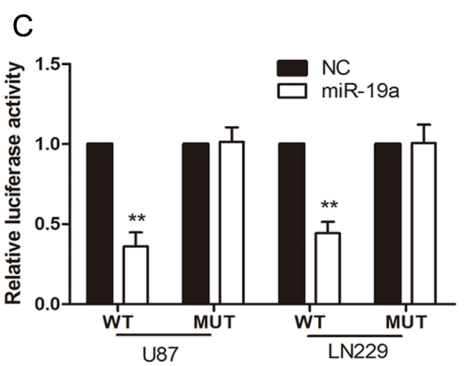

E Low

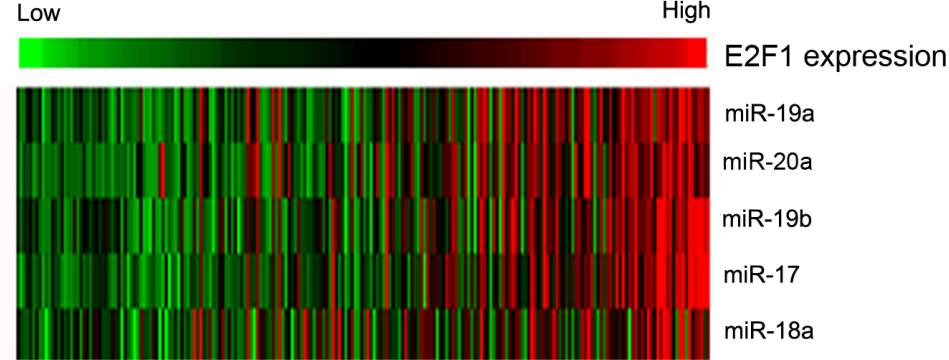

G

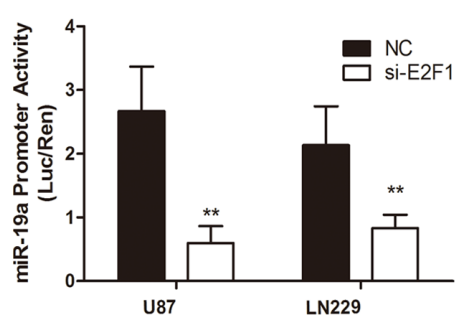

$\mathrm{H}$

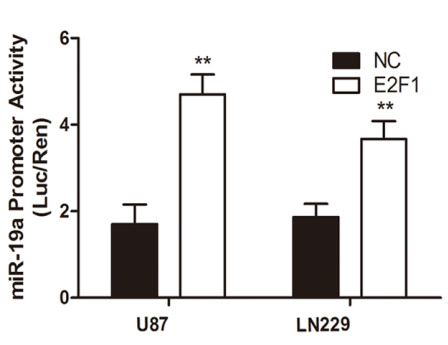

Figure 3: PPAR $\alpha$ is negatively regulated by E2F1/miR-19a signaling in glioma cells. (A) Schematic of the PPAR $\alpha$ 3'UTR including the putative binding sites for miR-19a, as predicted by TargetScan and Pictar algorithms. (B) PPAR $\alpha$ protein levels in U87 and LN229 cells at $48 \mathrm{~h}$ post-transfection. (C) MiR-19a down-regulated luciferase activity of wild-type PPAR $\alpha$ 3'UTR expression vector, but did not reduce expression of a mutant 3'UTR. (D) Heatmap showing the miR-17-92 cluster (including miR-19a) positively correlated with E2F1 in 158 glioma samples. (E) si-E2F1 decreases the expression of miR-19a in U87 and LN229 cells. (F) si-E2F1 inhibits miPPR-19a activity in a luciferase assay. (G) Increased E2F1 expression enhances miPPR-19a activity. 
The E2F family has been verified as a promising target gene related to the G1/S transition. E2F controls gene expression at $\mathrm{G} 1 / \mathrm{S}$ by activating genes that encode DNA replication proteins, enzymes that are responsible for deoxynucleotide biosynthesis, proteins that assemble to form functional origin complexes and kinases that are involved in the activation of initiation. E2F1 is a downstream regulator of the $\mathrm{Rb}$ pathway, which is capable of inducing cell proliferation and cell cycle progression [27-29]. Interestingly, E2F1 has multiple functions that could be considered to be either suppressing or promoting tumor development. Some previous studies support the role of E2F1 as a tumour suppressor rather than an oncogene [30, 31]. To date, the dysregulation, function, upstream regulators, and downstream effectors of E2F1 remain unclear. Recently, a cluster of miRNAs determining the regulation of E2F1 expression has been discovered. For example, members of the miR-17-92 cluster such as miR-20a and miR-17-5p inhibited E2F1 expression at the post-transcriptional level.
As a transcription factor, E2F1 increased the expression of microRNAs within the miR-17-92 cluster[32]. However, other studies, [33] including the present study, have identified E2F1 oncogenic functions in gliomas.

In this study, we used bioinformatic and integrative analytical approaches to detect the underlying function and molecular mechanism of PPAR $\alpha$ in glioma. The depletion of E2F1/miR-19a signaling inhibited glioma cell proliferation, invasion and aerobic glycolysis accompanying the downregulation of PPAR $\alpha$. MiR-19a was an important mediator between E2F1 and PPAR $\alpha$ through qRT-PCR, Western blot, and luciferase reporter assays. Increased miR-19a expression largely blocked the effect of si-E2F1 on PPAR $\alpha$ expression. Interestingly, E2F1 was regulated by $\operatorname{PPAR} \alpha$ through the p21 pathway, which can disrupt E2F/RB complexes by increasing RB phosphorylation and activating E2F1. However, the mechanism of how p21 is upregulated following PPAR $\alpha$ activation remains unclear. In human glioma samples,
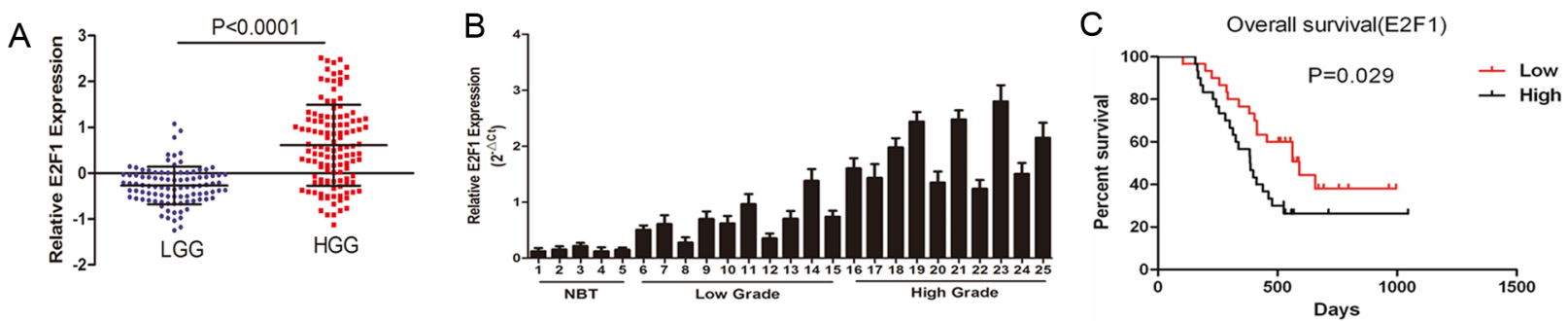

$\mathrm{D}$
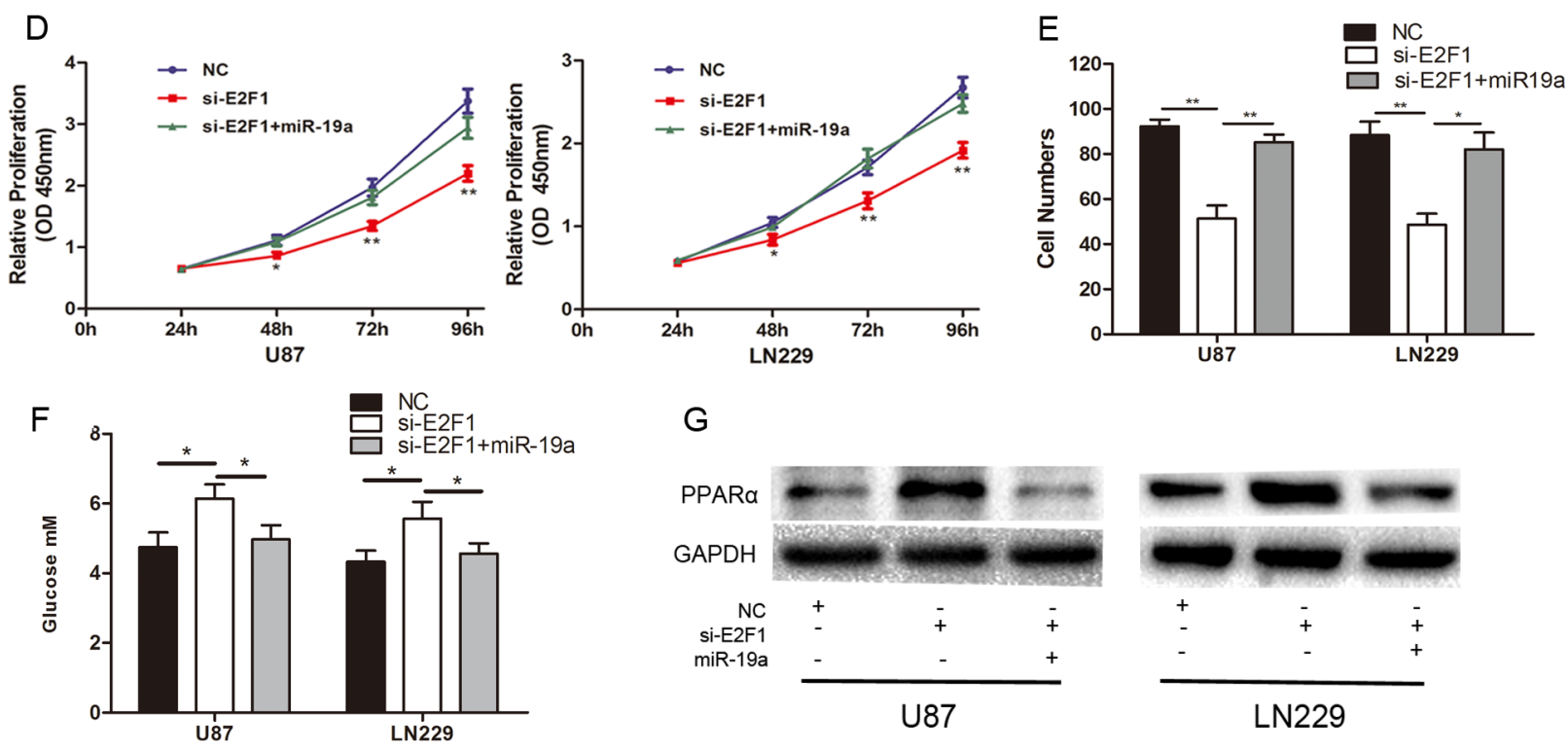

G

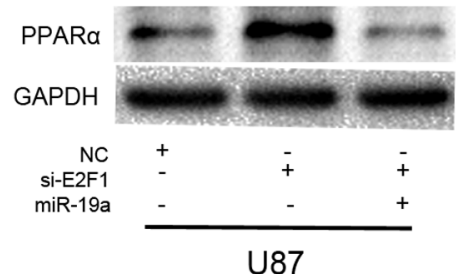

U87

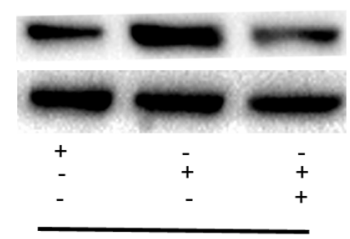

LN229

Figure 4: E2F1 affects the biological behavior of glioma cells, modulating PPARa in a miR-19a-dependent manner. (A) The levels of E2F1 were analyzed in glioma tissues of the CGGA glioma datasets (61 cases of LGG, 97 cases of HGG). (B) qRT-PCR confirmation of decreased E2F1 levels in HGG tissues compared with LGG tissues and normal brain tissues. (C) Kaplan-Meier survival curves for E2F1 expression in glioma tissues of the CGGA dataset. High expression of E2F1 confers a poor prognosis in glioma patients. (D) Decreased E2F1 suppressed the proliferation of glioma cells and its effects were blockedby miR-19a. (E) Decreased E2F1 suppressed the proliferation of glioma cells and its effects were blockedby miR-19a. (F) The invasiveness of U87 and LN229 cells was attenuated with the increased expression of E2F1. The effect of E2F1 on glioma cells is abolished by miR-19a. (G) Western blots identified that miR-19a could restore siE2F1 inducing PPAR $\alpha$ expression decreased. 

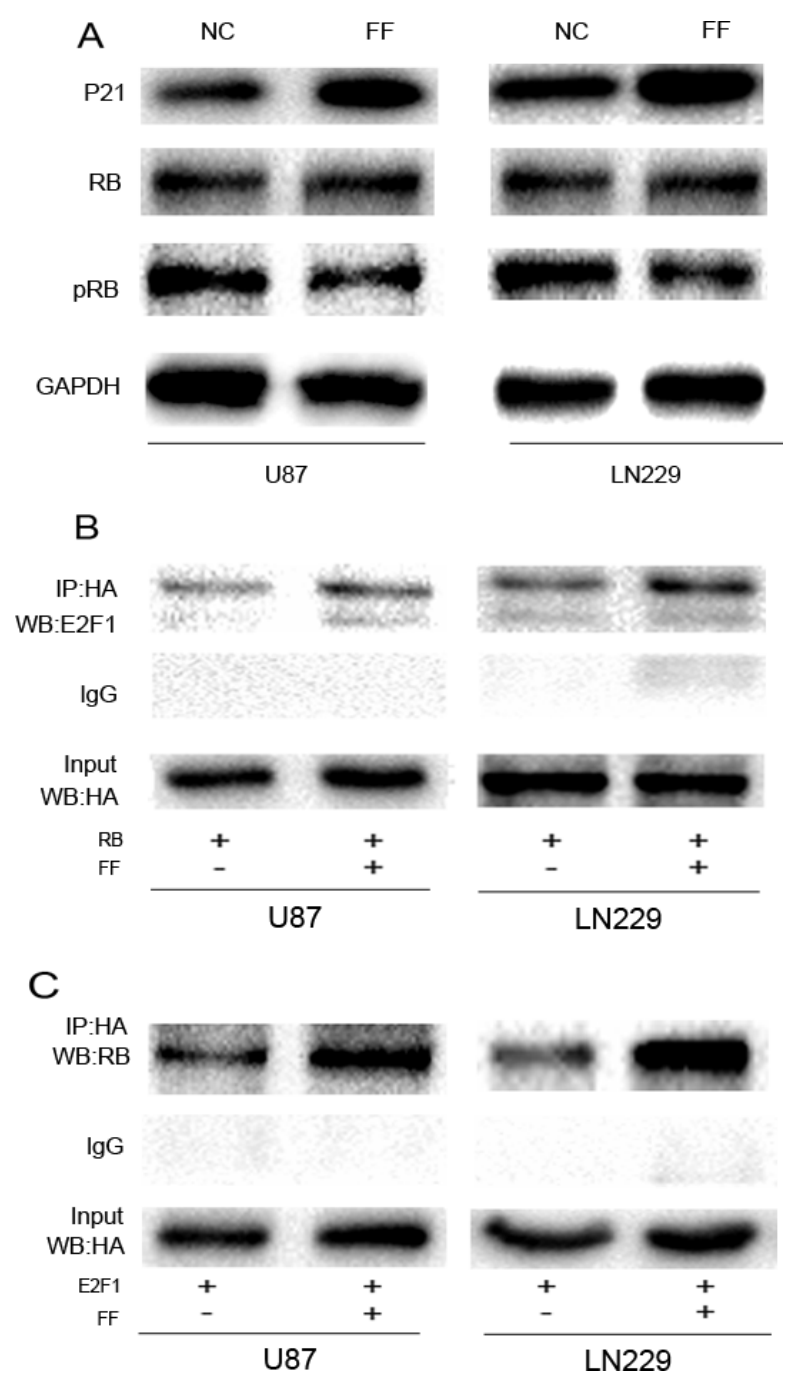

Figure 5: Active PPAR $\alpha$ feedback represses E2F1 activation. (A) PPAR $\alpha$ activation increases p16 and p21 protein levels and decreases CDKI-mediated pRB phosphorylation. $(\mathbf{B}, \mathbf{C})$ The PPAR $\alpha$ agonist fenofibrate promoted E2F1/RB complex formation in glioma cells.
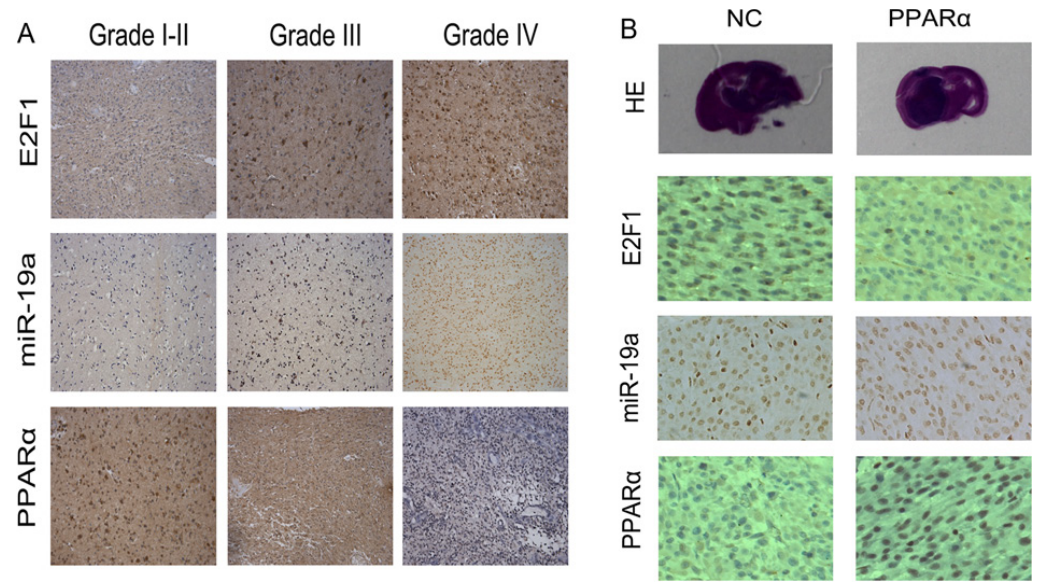

Figure 6: E2F1/ miR-19a/ PPARa signaling was confirmed in human glioma tissues and in nude mice orthotopic glioma model. (A) Expression of E2F1, miR-19a and PPAR $\alpha$ in human glioma tissues by IHC and ISH. (B) E2F1/ miR-19a/ PPAR $\alpha$ feedback loop was confirmed in nude mouse orthotopic glioma model. 
Pearson's correlations showed a significantly positive correlation between between E2F1 and miR-19a. An inverse correlation was detected between E2F1 and PPAR $\alpha$ levels, as well as miR-19a and PPAR $\alpha$. To our knowledge, we are the first to propose that the E2F1/miR-19a/PPAR $\alpha$ feedback loop is a key regulatory element in glioma. Further investigation into this feedback loop in glioma could lead to the identification of new therapeutic targets.

\section{MATERIALS AND METHODS}

\section{Tissue samples and microarray analysis}

Information on the tissue samples is described in Supplementary Materials and Methods. Microarray analysis was performed as previously described [34]. Glioma gene expression datasets are deposited at the Repository of Molecular Brain Neoplasia Data (REMBRANDT; http:// caintegrator.nci.nih.gov/rembrandt /) and the Gene Expression Omnibus Web site (http:// www.ncbi.nlm.nih. gov/geo/, accession nos. GSE4290).

\section{Cell lines and chemicals}

The human U87 and LN229 glioma cell lines used here were purchased from the Chinese Academy of Sciences Cell Bank. Both cells lines were cultured in Dulbecco's modified Eagle's medium (DMEM) (Gibco, USA) supplemented with $10 \%$ fetal bovine serum and maintained at $37^{\circ} \mathrm{C}$ in a $5 \% \mathrm{CO}_{2}$ incubator. In some experiments, PPAR $\alpha$ was activated by stimulating serumstarved cells with $100 \mu \mathrm{M}$ of fenofibrate (Gibco, USA).

\section{Gene knockdown and overexpression}

The 2'-O-methy1 (2' - OMe-) oligonucleotides were chemically synthesized by GenePharma (Shanghai, China). The sequences are as follows: 2'-OMe-hsa-miR19amimics (miR-19a), 5'-UGU GCA AAU CUA UGC AAA ACU GA-3'; E2F1 small interfering RNA (siRNA), 5'-CUG CAG AGC AGA UGG UUA UTT-3'; PPAR $\alpha$ SiRNA, 5'-UCA CGG AGC UCA CAG AAU UUU3' and 3'-AAU UCU GUG AGC UCC GUG AUU-5'; scrambled siRNA (negative control), 5'-UUC UCC GAA CGU GUC ACG UTT-3'; 2'-OMe-hsa-miR-19a inhibitor (AS-miR-19a), 5'-UCA GUU UUG CAU AGA UUU GCA CA-3'; and mircoRNA inhibitor negative control, 5'-CAG UAC UUU UGU GUA GUA CAA-3'. Oligonucleotides $(20 \mu \mathrm{M})$ were transfected into glioma cells using Lipofectamine 2000 (Invitrogen). The lentiviral vector Ubi-MCS-3FLAG-SV40-EGFP, containing the ORF of PPAR $\alpha(P P A R \alpha)$, was generated by GeneChem Inc. The empty lentiviral expression vector was used as a negative control. Oligonucleotides were complexed with Lipofectamine 2000 through OPTI-MEM (Invitrogen), subsequently added to glioma cells at a final concentration of $50 \mathrm{nmol} / \mathrm{L}$, and left to incubate. Then 8 hours later, the media was changed to DMEM. The E2F1-pSG5L-HA plasmid (Addgene plasmid 10736) and RB-pSG5L-HA (Addgene plasmid 10720) plasmid were obtained from Addgene (USA).

\section{Cell counting kit-8 (CCK8) assay and colony formation assay}

CCK8 assay: The cells were plated in 96-well plates in medium containing $10 \%$ FBS at approximately 5,000 cells per well $24 \mathrm{~h}$ after transfection. Subsequently, oligonucleotides were transfected or fenofibrate (Sigma, USA) was added into the cells. After $24 \mathrm{~h}, 48 \mathrm{~h}, 72 \mathrm{~h}$, and $96 \mathrm{~h}, 10 \mu \mathrm{l}$ of CCK8 (Beyotime, China) was added into each well and then the cells were incubated at $37^{\circ} \mathrm{C}$ for an additional $3 \mathrm{~h}$. The optical density was measured at $450 \mathrm{~nm}$ wave length. Colony formation assay: The cells were plated in triplicate in $60 \mathrm{~mm}$ plates in the presence of blank lentiviral vector or lentiviral- PPAR $\alpha$ for 14 days until the colonies were sufficiently large for visualization. Colonies were then fixed in methanol for $10 \mathrm{~min}$ and stained with $0.1 \%$ crystal violet for $10 \mathrm{~min}$.

\section{In vitro invasion assay}

The cells were transfected with oligonucleotides and incubated at $37^{\circ} \mathrm{C}$ for 48 hours, and then we transfer the cells were transferred to the top chambers Matrigel-coated invasion chambers (24-well insert, 8 - $\mu$ m pore size, BD Biosciences, San Jose, USA) in a serum-free DMEM and the medium containing $10 \%$ fetal bovine serum was added to the lower chamber to function as the chemoattractant. After incubating for $24 \mathrm{~h}$, the remaining cells in the chambers were removed using cotton swabs and the invading cells on the lower surface of the chambers were fixed with $95 \%$ ethanol, stained with $0.1 \%$ crystal violet, and photographed $(\times 200)$ in three independent fields for each well. Tests were repeated via three independent experiments.

\section{Glucose assay}

Cells were seeded into 6 -well plates at $3 \times 10^{5}$ cells per well in $2 \mathrm{ml}$ of supplemented DMEM. Subsequently, oligonucleotides were transfected or fenofibrate was added to the cells. After 48 h, $2 \mu$ l of supplemented DMEM was added into a series of well on a 96-well plate. The glucose assay was described in Supplementary Materials and Methods.

\section{RNA extraction and quantitative RT -PCR}

RNA was extracted from the cells after transfection or from tissues using TRIzol (Invitrogen). The E2F1 and PPAR $\alpha$ (qRT-PCR) reactions were performed using Fermentas reverse transcription reagents and 
SYBR Green PCR Master Mix (Applied Biosystems) according to the manufacturer's protocols. GAPDH was used for normalization. MiR-19a qRT-PCR reactions were performed using TaqMan miRNA assays (Applied Biosystems). U6 was used for normalization. And analysis was performed using the $2^{-\Delta \mathrm{Ct}}$ or $2^{-\Delta \Delta \mathrm{Ct}}$ method. Each experiment was performed in triplicate.

\section{Co- immunoprecipitation (co-IP)}

For Co-IP, U87 and LN229 cells seeded in $100 \mathrm{~mm}$ plates were transfected with E2F1-pSG5L-HA (Addgene plasmid 10736) or RB-pSG5L-HA (Addgene plasmid 10720). Cells were treated with or without $100 \mu \mathrm{M}$ Fenofibrate $24 \mathrm{~h}$ post-transfection, and lysed for $30 \mathrm{~min}$ in lysis buffer $48 \mathrm{~h}$ post-transfection. Lysate supernatants prepared as above were incubated with $20 \mu \mathrm{l}$ mouse antiHA antibody and washed protein $\mathrm{A} / \mathrm{G}$ agarose beads (Santa Cruz, USA) overnight at $4^{\circ} \mathrm{C}$ under continuous agitation. The beads were subsequently washed four times with the lysis buffer. Bound proteins were eluted with SDS loading buffer by boiling for $5 \mathrm{~min}$ and were subjected to western blot assay.

\section{Western blotting}

Western bloting was performed as previously described [35]. Immunoblots were performed using appropriate primary antibodies: E2F1 (1:500, Abcam, UK); PPAR alpha (1:500, Abcam, UK), phospho-Akt, Akt, phospho-extracellular signal-regulated kinase (Erk) 1/2 and anti-Erk1/2 (all from Santa Cruz, USA); and phosphor-RB, RB, p16, p21 (all from CST, USA), GAPDH (1:1000, CST, USA).

\section{Luciferase reporter assay}

The 3'-UTR of PPAR $\alpha$ containing the putative miR19a binding sequences was cloned into a firefly luciferase reporter construct. The $3^{\prime}$-UTR of PPAR $\alpha$ without the putative miR-675 binding sequences was used as mutated controls (Invitrogen). Luciferase activity was measured using the Dual-Luciferase Reporter Assay System (Promega, USA). MiR-19a promoter-containing (miPPR19a-containing) pGL3-Basic plasmids and mutated plasmids were constructed (SunShineBio Inc), as described previously [32]. Luciferase activity was measured using the Dual-Luciferase Reporter Assay System. (Promega, USA).

\section{Xenograft tumor assay}

Bagg albino (BALB) nude mice at 4 weeks of age were purchased from the Animal Center of the Cancer Institute at the Chinese Academy of Medical Science. The guidelines for animal welfare were approved by the Ethics Committee on Animal Research of Tianjin Medical University which was performed as previously described
[36]. To establish intracranial gliomas, $0.5 \times 10^{5} \mathrm{U} 87$ cells were transduced with PPAR $\alpha$ overexpression luciferase lentivirus and then implanted stereotactically. Mice were imaged for Fluc activity using bioluminescence imaging on days 10, 20, and 30 [36, 37]. All mice were divided randomly into two groups: a control group and a PPAR $\alpha$ overexpression group.

\section{Immunohistochemistry staining and in situ hybridization}

Immunohistochemistry staining and in situ hybridization is described in Supplementary Materials and Methods

\section{Statistical analysis}

All experiments were performed three times. Data were analyzed using SPSS 10.0. Statistical evaluation of the data was performed using one-way analysis of variance (ANOVA) for 3-group comparisons and $t$-tests for 2-group comparisons. The Pearson correlation analysis was performed using Matlab software. $P<0.05$ was considered statistically significant.

\section{ACKNOWLEDGMENTS AND FUNDING}

This work was supported by grants from the National High Technology Research and Development Program of China (863) (2012AA02A508), International Cooperation Program (2012DFA30470), National Natural Science Foundation of China (81502168, 91229121, 81272792, 81172389, 81372709, 81302185, 81101901), Jiangsu Province's Key Provincial Talents Program (RC2011051), Jiangsu Province's Key Discipline of Medicine (XK201117), Jiangsu Provincial Special Program of Medical Science (BL2012028), and Program for Development of Innovative Research Team in the First Affiliated Hospital of NJMU, and the Priority Academic Program Development of Jiangsu Higher Education Institutions (PAPD).

\section{CONFLICTS OF INTEREST}

None.

\section{REFERENCES}

1. Issemann I, Green S. Activation of a member of the steroid hormone receptor superfamily by peroxisome proliferators. Nature. 1990; 347:645-650.

2. Kliewer SA, Xu HE, Lambert MH, Willson TM. Peroxisome proliferator-activated receptors: from genes to physiology. Recent Prog Horm Res. 2001; 56:239-263.

3. Willson TM, Brown PJ, Sternbach DD, Henke BR. The PPARs: from orphan receptors to drug discovery. J Med Chem. 2000; 43:527-550. 
4. Kliewer SA, Umesono K, Noonan DJ, Heyman RA, Evans RM. Convergence of 9-cis retinoic acid and peroxisome proliferator signalling pathways through heterodimer formation of their receptors. Nature. 1992; 358:771-774.

5. Kersten S, Mandard S, Escher P, Gonzalez FJ, Tafuri S, Desvergne B, Wahli W. The peroxisome proliferatoractivated receptor alpha regulates amino acid metabolism. FASEB J. 2001; 15:1971-1978.

6. Berger J, Moller DE. The mechanisms of action of PPARs. Annu Rev Med. 2002; 53:409-435.

7. Shearer BG, Hoekstra WJ. Recent advances in peroxisome proliferator-activated receptor science. Curr Med Chem. 2003; 10:267-280.

8. Peters JM, Cattley RC, Gonzalez FJ. Role of PPAR alpha in the mechanism of action of the nongenotoxic carcinogen and peroxisome proliferator Wy-14,643. Carcinogenesis. 1997; 18:2029-2033.

9. Bentley P, Calder I, Elcombe C, Grasso P, Stringer D, Wiegand HJ. Hepatic peroxisome proliferation in rodents and its significance for humans. Food Chem Toxicol. 1993; 31:857-907.

10. Collett GP, Betts AM, Johnson MI, Pulimood AB, Cook S, Neal DE, Robson CN. Peroxisome proliferatoractivated receptor alpha is an androgen-responsive gene in human prostate and is highly expressed in prostatic adenocarcinoma. Clin Cancer Res. 2000; 6:3241-3248.

11. Suchanek KM, May FJ, Robinson JA, Lee WJ, Holman NA, Monteith GR, Roberts-Thomson SJ. Peroxisome proliferator-activated receptor alpha in the human breast cancer cell lines MCF-7 and MDA-MB-231. Mol Carcinog. 2002; 34:165-171.

12. Abu Aboud O, Wettersten HI, Weiss RH. Inhibition of PPARalpha induces cell cycle arrest and apoptosis, and synergizes with glycolysis inhibition in kidney cancer cells. PLoS One. 2013; 8:e71115.

13. Tanaka T, Kohno H, Yoshitani S, Takashima S, Okumura A, Murakami A, Hosokawa M. Ligands for peroxisome proliferator-activated receptors alpha and gamma inhibit chemically induced colitis and formation of aberrant crypt foci in rats. Cancer Res. 2001; 61:2424-2428.

14. Saidi SA, Holland CM, Charnock-Jones DS, Smith SK. In vitro and in vivo effects of the PPAR-alpha agonists fenofibrate and retinoic acid in endometrial cancer. Mol Cancer. 2006; 5:13.

15. Jiao HL, Zhao BL. Cytotoxic effect of peroxisome proliferator fenofibrate on human HepG2 hepatoma cell line and relevant mechanisms. Toxicol Appl Pharmacol. 2002; 185:172-179.

16. Grabacka M, Placha W, Plonka PM, Pajak S, Urbanska K, Laidler P, Slominski A. Inhibition of melanoma metastases by fenofibrate. Arch Dermatol Res. 2004; 296:54-58.

17. Grabacka M, Plonka PM, Urbanska K, Reiss K. Peroxisome proliferator-activated receptor alpha activation decreases metastatic potential of melanoma cells in vitro via downregulation of Akt. Clin Cancer Res. 2006; 12:3028-3036.
18. Peters JM, Cheung C, Gonzalez FJ. Peroxisome proliferatoractivated receptor-alpha and liver cancer: where do we stand? J Mol Med (Berl). 2005; 83:774-785.

19. Sylvestre Y, De Guire V, Querido E, Mukhopadhyay UK, Bourdeau V, Major F, Ferbeyre G, Chartrand P. An E2F/ miR-20a autoregulatory feedback loop. J Biol Chem. 2007; 282:2135-2143

20. Gizard F, Amant C, Barbier O, Bellosta S, Robillard R, Percevault F, Sevestre H, Krimpenfort P, Corsini A, Rochette J, Glineur C, Fruchart JC, Torpier G, et al. PPAR alpha inhibits vascular smooth muscle cell proliferation underlying intimal hyperplasia by inducing the tumor suppressor p16INK4a. J Clin Invest. 2005; 115:3228-3238.

21. Nobori T, Miura K, Wu DJ, Lois A, Takabayashi K, Carson DA. Deletions of the cyclin-dependent kinase-4 inhibitor gene in multiple human cancers. Nature. 1994; 368:753-756.

22. Sherr CJ, Roberts JM. CDK inhibitors: positive and negative regulators of G1-phase progression. Genes Dev. 1999; 13:1501-1512.

23. Serrano M, Hannon GJ, Beach D. A new regulatory motif in cell-cycle control causing specific inhibition of cyclin D/ CDK4. Nature. 1993; 366:704-707.

24. Harbour JW, Dean DC. Rb function in cell-cycle regulation and apoptosis. Nat Cell Biol. 2000; 2:E65-67.

25. Grau R, Punzon C, Fresno M, Iniguez MA. Peroxisomeproliferator-activated receptor alpha agonists inhibit cyclo-oxygenase 2 and vascular endothelial growth factor transcriptional activation in human colorectal carcinoma cells via inhibition of activator protein-1. Biochem J. 2006; $395: 81-88$.

26. Panigrahy D, Kaipainen A, Huang S, Butterfield CE, Barnes CM, Fannon M, Laforme AM, Chaponis DM, Folkman J, Kieran MW. PPARalpha agonist fenofibrate suppresses tumor growth through direct and indirect angiogenesis inhibition. Proc Natl Acad Sci USA. 2008; 105:985-990.

27. Gorgoulis VG, Zacharatos P, Mariatos G, Kotsinas A, Bouda M, Kletsas D, Asimacopoulos PJ, Agnantis N, Kittas C, Papavassiliou AG. Transcription factor E2F-1 acts as a growth-promoting factor and is associated with adverse prognosis in non-small cell lung carcinomas. J Pathol. 2002; 198:142-156.

28. Eymin B, Gazzeri S, Brambilla C, Brambilla E. Distinct pattern of E2F1 expression in human lung tumours: E2F1 is upregulated in small cell lung carcinoma. Oncogene. 2001; 20:1678-1687.

29. Suh DS, Yoon MS, Choi KU, Kim JY. Significance of E2F-1 overexpression in epithelial ovarian cancer. Int J Gynecol Cancer. 2008; 18:492-498.

30. Yamasaki L, Jacks T, Bronson R, Goillot E, Harlow E, Dyson NJ. Tumor induction and tissue atrophy in mice lacking E2F-1. Cell. 1996; 85:537-548. 
31. Field SJ, Tsai FY, Kuo F, Zubiaga AM, Kaelin WG, Jr., Livingston DM, Orkin SH, Greenberg ME. E2F-1 functions in mice to promote apoptosis and suppress proliferation. Cell. 1996; 85:549-561.

32. Woods K, Thomson JM, Hammond SM. Direct regulation of an oncogenic micro-RNA cluster by E2F transcription factors. J Biol Chem. 2007; 282:2130-2134.

33. Alonso MM, Alemany R, Fueyo J, Gomez-Manzano C. E2F1 in gliomas: a paradigm of oncogene addiction. Cancer Lett. 2008; 263:157-163.

34. Tao T, Wang Y, Luo H, Yao L, Wang L, Wang J, Yan W, Zhang J, Wang H, Shi Y, Yin Y, Jiang T, Kang C, et al. Involvement of FOS-mediated miR-181b/miR-21 signalling in the progression of malignant gliomas. Eur J Cancer. 2013; 49:3055-3063.
35. Zhang C, Zhang J, Hao J, Shi Z, Wang Y, Han L, Yu S, You Y, Jiang T, Wang J, Liu M, Pu P, Kang C. High level of miR-221/222 confers increased cell invasion and poor prognosis in glioma. J Transl Med. 2012; 10:119.

36. Zhang JX, Han L, Bao ZS, Wang YY, Chen LY, Yan W, Yu SZ, Pu PY, Liu N, You YP, Jiang T, Kang CS, Chinese Glioma Cooperative G. HOTAIR, a cell cycle-associated long noncoding RNA and a strong predictor of survival, is preferentially expressed in classical and mesenchymal glioma. Neuro-oncology. 2013; 15:1595-1603.

37. Xu D, Jia Q, Li Y, Kang C, Pu P. Effects of Gamma Knife surgery on C6 glioma in combination with adenoviral p53 in vitro and in vivo. J Neurosurg. 2006; 105:208-213. 